\section{Tegafur-induced acral hyperpigmentation}

\author{
Vera Teixeira, Ricardo Vieira, \\ Américo Figueiredo \\ Department of Dermatology, Coimbra \\ University Hospital, Portugal
}

\begin{abstract}
Tegafur is a prodrug of 5-fluorouracil (5-FU) with a similar spectrum of antitumor activity. It is used in the treatment of advanced gastrointestinal neoplasms. Over 5-FU, tegafur has the advantage of oral administration and less hematologic toxicity. Gastrointestinal toxicity is its main dose-limiting factor. The cutaneous adverse effects of tegafur include mucositis, photosensitivity, diffuse or nail-restricted hyperpigmentation, palmoplantar erythrodysesthesia syndrome, palmoplantar keratoderma, sclerodactyly and Raynaud phenomenon. We report here the case of a patient who developed acral hyperpigmentation during treatment with tegafur.
\end{abstract}

\section{Case Report}

A 48-year-old woman, phototype $\mathrm{V}$, with an advanced rectal adenocarcinoma stage $\mathrm{C}$ (Duke's classification) diagnosed in December 2009, who developed acral hyperpigmentation during tegafur intake. Radio-therapy and chemotherapy (including tegafur) were initiated as neoadjuvant agents followed by rectal anterior resection. Tegafur $(500 \mathrm{mg} / \mathrm{d})$ was reintroduced one month after surgery. Four months later, the patient appeared with multiple $2-10 \mathrm{~mm}$ round and oval-shaped brown macules on the face (Figure 1), tongue (Figure 2A), hands, soles and nails. Almost all nails were involved, and longitudinal melano-nychia was identified in the $2^{\text {nd }} \mathrm{e} 3^{\text {rd }}$ fingernails of her right hand (Figure 2B). The skin biopsy revealed mild basal pigmentation. The diagnosis of tegafur-induced hiperpigmentation was made. One month after discontinuation of tegafur, the hyperpigmented acral lesions began to clear.

\section{Discussion}

The cutaneous adverse effects of tegafur include mucositis, photosensitivity, diffuse or nail-restricted hyperpigmentation, palmoplantar erythrodysesthesia syndrome, palmoplantar keratoderma, sclerodactyly and Raynaud phenomenon ${ }^{1-4}$. Hyperpigmentation of the skin, mucosa and nails is a side effect associated with various chemotherapy drugs, including 5 FU and its prodrugs. ${ }^{5}$ The time course of tegafur therapy, the cutaneous reaction and its clearance after discontinuing the treatment suggest a causal relationship based on chronological criteria. The cause of such pigmentation is unknown, although there may be a mechanism common to other chemotherapy drugs. These substances may increase pigmentation by direct or MSH-mediated stimulation of melanocytes. ${ }^{6}$ In 1991, Llistosella et col. proposed a mixed mechanism involving melanocyte hyperplasia and a decreased keratinocyte turnover, as basal pigmentation and dermal melanophages were observed histologically. ${ }^{1}$

Clinicians should be aware of this side effect of tegafur, since it is being increasingly used in patients with advanced colon cancer.

\section{References}

1. Llistosella E, Codina A, Alvarez R, et al. Tegafur-induced acral hyperpigmentation. Cutis 1991;48: 205-7.

2. Rios-Buceta L, Buezo GF, Peñas PF, et al. Palmo-plantar Erythrodysaesthesia Syndrome and Other Cutaneous Side-effects after Treatment with Tegafur. Acta Derm Venereol 1996;77:80-1.

3. Jucglà A, Sais G, Navarro M, et al. Palmoplantar keratoderma secondary to chronic acral erythema due to tegafur. Arch Dermatol 1995; 131:364-5.

4. Seishima M, Izumi T, Kanoh H. Raynaud's phenomenon possibly induced by a compound drug of tegafur and uracil. Eur $\mathrm{J}$ Dermatol 2000;10:55-8.

5. Revenga F. Cutaneous side-effects caused by Tegafur. Int J Dermatology 1999;38: 955-6.

6. Fukushima S, Hatta N. Atypical moles in patient undergoing chemotherapy with oral 5-fluorouracil prodrug. Br J Dermatol 2004;151:698-700.

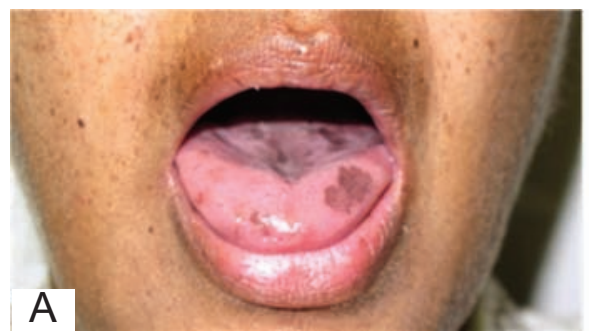

Figure 2. Hyperpigmentation on the tongue (A) and longitudinal melanonychia in the $2^{\text {nd }}$ e $3^{\text {rd }}$ fingernails (B).

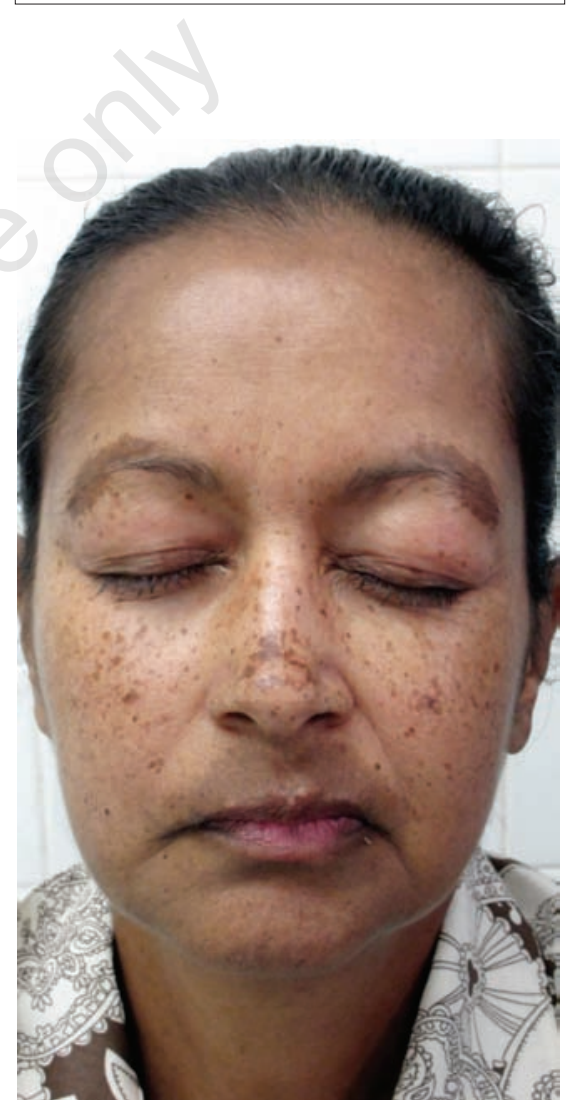

Figure 1. Brown macules on the face.

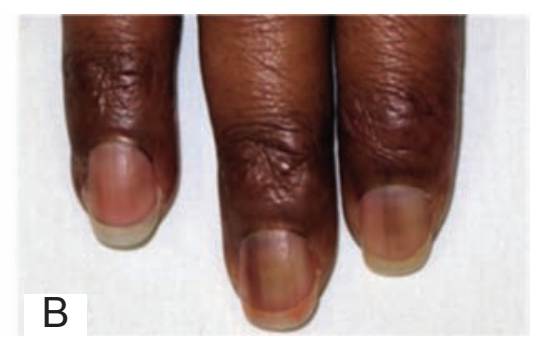

Correspondence: Vera Teixeira, Serviço de Dermatologia, Hospitais da Universidade de Coimbra, Praceta Mota Pinto, 3000-075 Coimbra, Portugal. E-mail: verafmup@hotmail.com

Key words: tegafur, 5-fluorouracil, acral hyperpigmentation.

Received for publication: 23 August 2011.

Accepted for publication: 24 August 2011.

This work is licensed under a Creative Commons Attribution NonCommercial 3.0 License (CC BYNC 3.0).

(C) Copyright V. Teixeira et al., 2011

Licensee PAGEPress, Italy

Dermatology Reports 2011; 3:e30

doi:10.4081/dr.2011.e30 